\title{
Cardiovascular safety of linagliptin in type 2 diabetes: a comprehensive patient-level pooled analysis of prospectively adjudicated cardiovascular events
}

\author{
Julio Rosenstock', Nikolaus Marx², Dietmar Neubacher ${ }^{3}$, Thomas Seck ${ }^{4}$, Sanjay Patel ${ }^{5}$, Hans-Juergen Woerle ${ }^{4}$ \\ and Odd Erik Johansen ${ }^{6^{*}}$
}

\begin{abstract}
Background: The cardiovascular (CV) safety of linagliptin was evaluated in subjects with type 2 diabetes (T2DM). Methods: Pre-specified patient-level pooled analysis of all available double-blind, randomized, controlled trials, $\geq 12$ weeks' duration (19 trials, 9459 subjects) of linagliptin versus placebo/active treatment. Primary end point: composite of prospectively adjudicated CV death, non-fatal myocardial infarction, non-fatal stroke, and hospitalization for unstable angina (4P-MACE). Hospitalization for congestive heart failure (CHF) was also evaluated; adjudication of CHF was introduced during the phase 3 program (8 trials; 3314 subjects). 4P-MACE was assessed in placebo-controlled trials (subgroup of 18 trials; 7746 subjects). Investigator-reported events suggestive of CHF from 24 placebo-controlled trials (including trials $<12$ weeks' duration, 8778 subjects) were also analyzed.

Results: 5847 patients received linagliptin (5 mg: 5687, $10 \mathrm{mg}: 160)$ and 3612 comparator (glimepiride: 775, voglibose: 162, placebo: 2675); cumulative exposure, 4421.3 and 3254.7 patient-years, respectively. 4P-MACE incidence rates: 13.4 per 1000 patient-years, linagliptin (60 events), 18.9, total comparators (62 events); overall hazard ratio (HR), 0.78 (95\% confidence interval [Cl], 0.55-1.12). HR for adjudicated hospitalization for CHF $(n=21)$ : 1.04 (0.43-2.47). For placebo-controlled trials, 4P-MACE incidence rates: 14.9 per 1000 patient-years, linagliptin (43 events), 16.4, total comparators (29 events); overall HR, 1.09 ( $95 \% \mathrm{Cl}, 0.68-1.75)$. Occurrence of investigator-reported events suggestive of CHF was low for linagliptin- ( 26 events, $0.5 \%$; serious: 16 events, $0.3 \%$ ) and placebo-treated ( 8 events, $0.2 \%$; serious: 6 events, $0.2 \%$ ) patients.
\end{abstract}

Conclusions: Linagliptin is not associated with increased CV risk versus pooled active comparators or placebo in patients with T2DM.

Keywords: Drug safety, Linagliptin, Adverse effects, Type 2 diabetes mellitus

\section{Background}

Cardiovascular $(\mathrm{CV})$ disease $(\mathrm{CVD})$ is the major cause of premature death in patients with type 2 diabetes mellitus (T2DM), with approximately half of all deaths attributable to CV complications [1,2]. An important consideration in the treatment of T2DM is the management of $\mathrm{CV}$ risk factors, including hyperglycemia, being closely and independently associated with increased CV

\footnotetext{
* Correspondence: odd_erik.johansen@boehringer-ingelheim.com ${ }^{6}$ Boehringer Ingelheim, Drengsrudbekken 8, 1373 Asker, Oslo, Norway Full list of author information is available at the end of the article
}

morbidity and premature mortality [3]. Evaluation of the CV effects of drugs used to lower blood glucose in T2DM is important, as illustrated by the controversy surrounding certain glucose-lowering drugs, such as rosiglitazone [4]. For other drugs, in particular the sulfonylureas (SUs) [5], the CV safety is contentious, with some reports suggesting an increased CV risk with certain SUs [6-8], while others report no increased risk $[9,10]$. Given the relationship between CV safety and T2DM and the uncertainty surrounding the $\mathrm{CV}$ risk of some therapies, the US Food and Drug Administration 
(FDA) requires evaluation of $\mathrm{CV}$ risk for new compounds being developed as therapies for T2DM [11]. Consequently, several trials are currently under way to evaluate the long-term $\mathrm{CV}$ outcomes of recently developed drugs. The first 2 placebo-controlled trials (SAVOR-TIMI 53 and EXAMINE) involving the dipeptidyl peptidase (DPP)-4 inhibitors saxagliptin and alogliptin, respectively, both reported a neutral effect on a composite of $\mathrm{CV}$ death (including fatal stroke and fatal myocardial infarction [MI]), non-fatal MI, and non-fatal stroke (3P-MACE) $[12,13]$. Neither SAVOR-TIMI 53 nor EXAMINE showed an increase in death from any cause versus placebo (hazard ratio $[\mathrm{HR}], 1.11,95 \%$ confidence interval [CI], 0.96-1.27; $P=.15$, and $\mathrm{HR}, 1.03,95 \% \mathrm{CI}, 0.87-1.22$; $P=.72$, respectively) or death from CV causes (HR, 0.79, 95\% CI, 0.60-1.04; $P=.10$, and HR, 0.88, 95\% CI, 0.71$1.09 ; P=.23$, respectively). Of note, a statistically significant increased risk for hospitalization for congestive heart failure (CHF) associated with saxagliptin therapy was reported, and an analysis of data for alogliptin showed a non-significant $H R$ above 1.0 [14]. A recent analysis of the end point of hospitalization for heart failure in SAVORTIMI 53 showed that saxagliptin therapy was associated with an increased risk of this event: more patients treated with saxagliptin $(289,3.5 \%)$ were hospitalized for heart failure compared with those allocated to placebo (228, 2.8\%; HR, 1.27; 95\% CI, 1.07-1.51; $P=.007$ ) [15]. This increase was greatest among patients with elevated levels of natriuretic peptides at baseline, previous heart failure, or chronic kidney disease. At present it remains unclear whether any potential increase in CHF is a causal effect.

Linagliptin is a selective and potent DPP-4 inhibitor with a xanthine-based molecular structure, and is indicated for the treatment of T2DM. The pharmacokinetic properties of linagliptin permit DPP-4 inhibition over 24 hours following once-daily dosing, and the drug is primarily excreted via the bile and gut $[16,17]$. In 2010, a pre-specified meta-analysis of $\mathrm{CV}$ events from 8 phase 3 studies was performed for linagliptin versus overall comparator-treated patients with T2DM [18]. All suspected CV events and fatalities were prospectively adjudicated by a blinded, independent clinical event committee (CEC). The primary end point was a composite of $\mathrm{CV}$ death, stroke, MI, and hospitalization for unstable angina (4P-MACE). Although the analysis was limited in terms of patient numbers $(\mathrm{n}=$ $5239)$ as well as total number of primary events $(n=34)$, this initial pooled $\mathrm{CV}$ analysis did not indicate any increased risk of CV events with linagliptin.

Following completion of several other phase 3 studies of linagliptin, contributing to a larger database than was previously available, the pooled analysis presented here provides a more comprehensive and up-to-date assessment of the CV safety profile of linagliptin versus comparator treatments in patients with T2DM. In addition, investigator-reported events suggestive of $\mathrm{CHF}$ are presented, using a pooling of 24 placebo-controlled trials.

\section{Methods}

\section{Study selection}

The first cohort analyzed included all available, completed phase 3 studies and 1 phase $2 \mathrm{~b}$ study in the Boehringer Ingelheim (BI) project database for linagliptin (for study details, see Table 1) in which an independent adjudication of $\mathrm{CV}$ events (MACE-plus, defined as a composite end point consisting of the following adjudicated events: CV death, non-fatal MI, non-fatal stroke, and hospitalization for unstable angina) was conducted (the 8 trials with prospective independent adjudication of hospitalization for CHF are identified in Table 1). All studies were conducted in accordance with Good Clinical Practice guidelines and the principles of the Declaration of Helsinki. This pooled patient-level analysis was pre-specified and included only double-blind, randomized, controlled trials, lasting $\geq 12$ weeks, evaluating linagliptin versus comparator (placebo or active treatment), with database lock-up to August 6, 2012. Data from all patients treated with a daily oral linagliptin dose of $5 \mathrm{mg}$ or more were pooled into a total comparator cohort with a common linagliptin treatment group, and all randomized control treatments were combined into 1 common control treatment group (regardless of whether patients were treated with placebo or an active comparator, as per methodology suggested by the FDA [11]). As a sensitivity analysis, the impact on the primary end point 4P-MACE and on hospitalization for $\mathrm{CHF}$ in the placebo cohort alone (ie, only trials or parts of trials in which linagliptin was compared with placebo) was also evaluated. In an additional analysis, the occurrence of symptoms or adverse events (AEs) suggestive of heart failure was evaluated, based on newly updated results from 24 placebo-controlled trials (phases 1-3; 3 of which were $<12$ weeks in duration), involving 8778 patients (5488 linagliptin and 3290 placebo) (for details of the additional trials included, see Table 1). Investigator-reported AEs that may be indicative of possible heart failure were defined using the list of terms defined in the Medical Dictionary for Regulatory Activities (MedDRA 16.0; narrow standardized MedDRA queries [SMQ] cardiac failure). AEreported terms coded to these specific MedDRA preferred terms were used to identify possible heart failure events.

\section{Analysis population}

Common inclusion criteria across the included trials were a diagnosis of T2DM, age $\geq 18$ years, glycated hemoglobin (HbA1c) 7-10\% entrance criterion in most studies, and body mass index (BMI) $20-45 \mathrm{~kg} / \mathrm{m}^{2}$. In all studies, if deterioration in glycemic control occurred, rescue therapy could be initiated. In general, rescue therapy was initiated if glucose levels exceeded 240, 200, or $180 \mathrm{mg} / \mathrm{dL}$ (after an overnight fast) on 2 separate days during the first 12, 12- 
Table 1 Overview of linagliptin clinical trials included in the CV safety analysis of adjudicated events

\begin{tabular}{|c|c|c|c|c|c|}
\hline $\begin{array}{l}\text { Study } \\
\text { number }\end{array}$ & Treatment & Patients & Background & Follow-up (weeks) & Reference/NCT number \\
\hline 1218.15 & Linagliptin 5 mg Placebo; & 259130 & Pioglitazone & 24 & Gomis et al. [39]. NCT00641043 \\
\hline 1218.16 & Linagliptin 5 mg Placebo; & 336167 & None & 24 & Del Prato et al. [40]. NCT00621140 \\
\hline 1218.17 & Linagliptin 5 mg Placebo; & 523177 & Metformin & 24 & Taskinen et al. [41]. NCT00601250 \\
\hline 1218.18 & Linagliptin 5 mg Placebo; & 792263 & Metformin + sulfonylurea & 24 & Owens et al. [42]. NCT00602472 \\
\hline 1218.20 & Linagliptin 5 mg Glimepiride 1-4 mg; & 776775 & Metformin & 104 & NCT00622284 \\
\hline 1218.23 & $\begin{array}{l}\text { Linagliptin } 5 \text { mg Linagliptin } 10 \text { mg } \\
\text { Voglibose } 0.6 \text { mg Placebo; }\end{array}$ & 15916016280 & None & 26 & NCT00654381 \\
\hline 1218.35 & Linagliptin 5 mg Placebo; & 15781 & Sulfonylurea & 18 & NCT00819091 \\
\hline $1218.36^{*}$ & Linagliptin 5 mg Placebo; & 628627 & Basal insulin & $\geq 52$ & NCT00954447 \\
\hline 1218.43 & Linagliptin 5 mg Placebo; & 6763 & None & 52 & NCT00800683 \\
\hline 1218.46 & Linagliptin 5 mg Placebo; & 428363 & Metformin & 24 & NCT00798161 \\
\hline 1218.50 & Linagliptin 5 mg Placebo; & 15176 & None & 52 & NCT00740051 \\
\hline $1218.52^{+}$ & Linagliptin 5 mg Placebo; & 396170 & Metformin & 54 & NCT00915772 \\
\hline $1218.61^{*}$ & Linagliptin 5 mg Placebo; & 18389 & Metformin + pioglitazone & 24 & NCT00996658 \\
\hline $1218.62^{*}$ & Linagliptin 5 mg Placebo; & 44744 & Metformin & 12 & NCT01012037 \\
\hline $1218.63^{*}$ & Linagliptin 5 mg Placebo; & 16279 & None & 24 & NCT01084005 \\
\hline $1218.64^{*}$ & Linagliptin 5 mg Placebo; & 113122 & None & 52 & NCT01087502 \\
\hline $1218.65^{*}$ & Linagliptin 5 mg Placebo; & 205100 & Metformin & 24 & NCT01215097 \\
\hline $1218.66^{*}$ & Linagliptin 5 mg Placebo; & 20099 & None & 24 & NCT01214239 \\
\hline $1218.75^{*}$ & Linagliptin 5 mg Placebo; & 101115 & None & 24 & NCT01194830 \\
\hline
\end{tabular}

*Trials with prospective independent adjudication of hospitalization for CHF.

${ }^{\dagger}$ Trial 1218.52 is an extension of study 1218.46 and was analyzed in conjunction with 1218.46 , and therefore is not displayed as an individual study in other displays. CV, cardiovascular; CHF, congestive heart failure.

24 , or $>24$ weeks, respectively. Data collected after initiation of rescue therapy were included in the analysis.

\section{Laboratory, BP, heart rate, and weight assessment}

Changes from baseline in blood pressure (BP), heart rate, weight, and lipid parameters (including total cholesterol, low-density lipoprotein [LDL] cholesterol, high-density lipoprotein [HDL] cholesterol, and triglycerides) to the last available on-treatment measurement were assessed.

\section{CV event data collection and adjudication}

Data on AEs were collected by the study investigators using electronic case report forms. During the pivotal phase 3 trials for linagliptin, a prospectively defined adjudication process was implemented to assess cardiac and neurological vascular events, including deaths, through 2 independent, blinded, external CECs, respectively, for cardiac events and neurological events. Adjudication for the event 'hospitalization for CHF' was introduced while the phase 3 program was in progress and, therefore, implemented for a limited number of studies (8 studies, involving 3314 patients $[n=2039$ linagliptin and $n=1275$ total comparators]; Table 2).

After identification of a trigger $\mathrm{AE}$, a data package for the CEC was prepared. This data package contained patient profile information (based on the demographic and clinical safety data in the clinical trial database); all available electrocardiograms and reports on angiography scans, ultrasound, or duplex scans or echocardiography, as appropriate; all available laboratory data; and other relevant medical documents. Based on these data packages, either the cardiac or neurology CEC performed the adjudication of the trigger event, blinded to treatment allocation, and documented the adjudication result. Upon completion of a trial, these adjudicated events were collected and included in the clinical trial database.

In the additional analysis, occurrence of events suggestive of CHF (narrow MedDRA 15.1 SMQ cardiac failure) was assessed from the investigator-reported AEs. It should be noted that the number of events suggestive of $\mathrm{CHF}$ reported from the investigators does not take into account the adjudication status of these cases and is not limited to events leading to hospitalization.

\section{End points}

The primary end point was time to the first occurrence of any components of the 4P-MACE composite. Secondary end points were composites of: (i) 3P-MACE; (ii) all adjudicated $\mathrm{CV}$ events, which included $\mathrm{CV}$ death, nonfatal MI, non-fatal stroke, unstable angina, stable angina, 
Table 2 FDA custom MACE end point

\begin{tabular}{ll}
\hline The following MedDRA preferred terms (version 15.0) are included \\
in the FDA custom MACE end point: \\
\hline Myocardial infarction terms & Stroke terms \\
Myocardial Infarction terms & Basilar artery thrombosis \\
Acute myocardial infarction & Brain stem infarction \\
Coronary artery thrombosis & Brain stem stroke \\
Myocardial infarction & Brain stem thrombosis \\
Papillary muscle infarction & Carotid arterial embolus \\
Postprocedural myocardial infarction & Carotid artery thrombosis \\
Silent myocardial infarction & Cerebellar infarction \\
& Cerebral artery embolism \\
& Cerebral artery thrombosis \\
& Embolic stroke \\
Haemorrhagic cerebral infarction & Haemorrhagic stroke \\
Haemorrhagic transformation stroke & Ischaemic cerebral infarction \\
Ischaemic stroke \\
Lacunar infarction \\
Lateral medullary syndrome \\
Moyamoya disease \\
Postprocedural stroke \\
Stroke in evolution \\
Thalamic infarction \\
Thrombotic cerebral infarction \\
Thrombotic stroke \\
Wallenberg syndrome \\
\hline
\end{tabular}

FDA, Food and Drug Administration; MACE, major adverse cardiovascular event.

and transient ischemic attacks (TIAs); (iii) FDA-defined custom major adverse $\mathrm{CV}$ events (MACE), derived from 34 MedDRA preferred terms for stroke and MI (these terms are listed in Table 2). Tertiary end points were the individual adjudicated end points (as listed above) plus coronary revascularization procedures, hospitalization for CHF, stent thrombosis, and all-cause mortality.

\section{Statistical analysis}

The analyses based on individual patient-level data in the treated set were defined as all patients who were randomized and received at least 1 dose of study medication. Changes in CV risk factors from baseline to last treatment were expressed descriptively. Overall incidences and incidence rates (per 1000 patient-years) were calculated for all end points in each of the pooled treatment groups within the treated set. The $\mathrm{CV}$ risk estimate after treatment with linagliptin in comparison with control treatment (and for 4P-MACE and CHF for placebo-controlled studies only) is expressed as HR for time to first event, using Cox proportional hazards model, with adjustments for treatment and study groups. Sensitivity analyses were performed to assess the impact of rescue medication on the analyses of the primary end point. Pre-specified subgroup analyses were performed to evaluate the incidence and incidence rates for the subgroup variables: age $(\leq 50,51$ to $<65,65$ to $<75$, and $\geq 75$ years), gender, race, use of rescue therapy, occurrence of hypoglycemia, Framingham 10-year coronary heart disease $(\mathrm{CHD})$ risk score $(\leq 15 \%$ or $>15 \%)$, renal function (estimated glomerular filtration rate [eGFR] according to Modification of Diet in Renal Disease [MDRD] formula), and microalbuminuria (albumin/creatinine ratio $[\mathrm{ACR}])$.

The number of patients with symptoms suggestive of CHF, based on the MedDRA narrow SMQ Cardiac failure, was reported descriptively.

\section{Results}

Patient characteristics and drug exposure

Pooled data on adjudicated events were evaluated from 19 studies (17 placebo-controlled, 1 with placebo/active control, 1 with active control only), which included 9459 patients treated with at least 1 dose of study drug. In total, 5847 patients were treated with linagliptin; the majority of subjects received the $5-\mathrm{mg}$ dose $(\mathrm{n}=5687)$ (in study 1218.23, 160 patients received linagliptin $10 \mathrm{mg}$ ). There were 3612 subjects in the comparator group: 937 received active treatment (glimepiride 1$4 \mathrm{mg}$ once daily [ $\mathrm{n}=775$ ] or voglibose $0.2 \mathrm{mg} 3$ times daily [ $\mathrm{n}=162]$ ) and 2675 received placebo. Depending on the design of the individual trial, some patients received their trial medication in addition to existing background glucose-lowering therapy. For the additional analysis of investigator-reported CHF, data from 24 placebo-controlled studies were evaluated (patients received linagliptin $5 \mathrm{mg}$ or placebo as monotherapy, or in addition to background therapies). This evaluation included data from 8778 patients (5488 linagliptin- and 3290 placebo-treated patients). An overview of the included trials is provided in Tables 1 and 3.

The overall median drug exposure in the linagliptin group, for the main pooled analysis, was 175 days (range: 1-776 days). Corresponding exposure in the placebo group was 174 days (range: 1-707 days), in the active comparator group, 729 days (range: 3-804 days), and in the combined comparator group, 183 days (range: 1-804 days). The percentages of patients who received trial medication for at least 52 weeks were $31.6 \%$ for placebo, $31.0 \%$ for linagliptin, $69.7 \%$ for active control, and $42.3 \%$ for combined comparators. Cumulative exposure (patient-years) was 4133.7 for linagliptin and 3106.6 for total comparators. 
Table 3 Overview of additional clinical trials included in evaluation of congestive heart failure (CHF)

\begin{tabular}{|c|c|c|c|c|c|}
\hline $\begin{array}{l}\text { Study } \\
\text { number }\end{array}$ & Treatment & Patients & Background & $\begin{array}{l}\text { Follow-up } \\
\text { (weeks) }\end{array}$ & Reference/NCT number \\
\hline 1218.2 & Linagliptin 1, 2.5, 5, 10 mg Placebo; & 359 & None & $<2$ & Heise et al. [43]. NCT02183350 \\
\hline 1218.3 & Linagliptin, 2.5, 5, 10 mg Placebo; & 6116 & None & 4 & Forst et al. [44]. NCT 02183415 \\
\hline 1218.5 & Linagliptin 0.5, 2.5, 5 mg Placebo; & 17067 & None & 30 & $\begin{array}{l}\text { Singh-Franco et al. [45]. } \\
\text { NCT00328172 }\end{array}$ \\
\hline 1218.6 & Linagliptin 1, 5, 10 mg Placebo; & 19771 & $\begin{array}{l}\text { Metformin (most received } \\
\geq 1500 \mathrm{mg} / \mathrm{d} \text { ) }\end{array}$ & 12 & Forst et al. [46]. NCT00309608 \\
\hline 1218.37 & Linagliptin 5 mg Placebo; & 4040 & None & 4 & Rauch et al. [47]. NCT00716092 \\
\hline 1264.3 & $\begin{array}{l}\text { Linagliptin } 5 \text { mg Pioglitazone } \\
\text { 15, 30, } 45 \text { mg Linagliptin + pioglitazone; }\end{array}$ & $\begin{array}{l}105284 \\
274\end{array}$ & None & Up to 54 & NCT01183013 \\
\hline
\end{tabular}

(Study 1218.20 in table was not included in the additional analysis, as this trial was not placebo-controlled).

Baseline characteristics were broadly similar across the treatment groups for the main pooled analysis (Table 4). More than half of the patients were white $(58.2 \%$, linagliptin group; $60.6 \%$, total comparator group) and male (54.4\% and $56.5 \%$, respectively). The majority of patients were older than 50 years of age $(78.0 \%$ and $78.4 \%$, respectively). Mean (SD) BMI was 29.04 (5.19) $\mathrm{mg} / \mathrm{kg}^{2}$ in the linagliptin group and $29.53(5.19) \mathrm{mg} / \mathrm{kg}^{2}$ in the total comparator group. More than half of the cohort (56.8\%) had a diagnosis of T2DM for $>5$ years, and the majority of patients $(83.1 \%)$ had previously received at least 1 glucose-lowering drug. For the 19 trials used in the main analysis, the distribution of $\mathrm{CV}$ risk factors at baseline was generally similar between the treatment groups, with Framingham risk $>15 \%$ recorded in 25\% and 29\% of patients in the linagliptin and total comparator groups, respectively. Corresponding frequencies of microalbuminuria (urinary albumin:creatinine ratio [UACR], $>30$ to $\leq 300 \mathrm{mg} / \mathrm{g}$ ) at baseline were $24.3 \%$ and $22.7 \%$, respectively.

The baseline characteristics of the dataset used for the additional evaluation of $\mathrm{CHF}$ showed similar findings (Table 5).

Active treatment produced a greater reduction in HbA1c compared with placebo. For CV risk factors evaluated (total cholesterol, LDL cholesterol, HDL cholesterol, triglycerides, systolic and diastolic BP, heart rate, and body weight), there were no meaningful differences between linagliptin and placebo or total comparators (Table 6).

\section{Adjudicated CV events}

Overall, 420 patients with AEs were identified from the pre-specified list of trigger events. A total of 60 (1.0\%) primary components of $4 \mathrm{P}-\mathrm{MACE}$ events were reported in the linagliptin group and $62(1.7 \%)$ in the comparator group. The incidence rate of 4P-MACE was 13.4 events per 1000 patient-years for linagliptin-treated patients compared with 18.9 in the active comparator group (Table 7, Figure 1) with a Cox regression HR (Table 8) indicating no significant difference between the 2 treatment groups; HR, 0.78 (95\% CI, 0.55-1.12) (Figure 2).

In the placebo cohort of the overall group (ie, 18 of the 19 trials), 4P-MACE incidence rates (Figure 3) were 14.9 per 1000 patient-years for linagliptin (43 events) and 16.4 for total comparators (29 events), yielding an overall HR of 1.09 (95\% CI, 0.68-1.75).

In the placebo cohort $(n=7746$ patients) there was no signal for an increased risk of either all-cause or $\mathrm{CV}$ mortality with linagliptin therapy. All-cause mortality for linagliptin (2538 patient years exposure) versus placebo (1608 patient years exposure) was reported for 13 versus 11 patients, respectively; HR 0.81 (95\% CI, 0.36-1.81). For CV mortality with linagliptin (2538 patient years exposure) versus placebo (1608 patient years exposure), 8 versus 6 deaths, respectively, were reported; HR 0.88 (0.30-2.55).

Subgroup analysis of the overall cohort showed that the risk estimate for the primary end point associated with linagliptin versus total comparators was not increased by the following factors: age, gender, race, use of rescue therapy, occurrence of hypoglycemia, Framingham 10-year CHD risk score $(\leq 15 \%$ or $>15 \%)$, renal function, microalbuminuria, or use of background medication (insulin and/or metformin) (Table 9).

In line with the results for the primary end point, the incidence rates and the HRs for the secondary end points were similar for linagliptin and total comparators (Tables 7 and 8). The overall risk estimates were also similar for tertiary end points for linagliptin and total comparators (Table 7, Figure 4), with a significantly reduced HR for stroke and TIA favoring linagliptin compared with total comparators. For hospitalization for $\mathrm{CHF}$, a small number of patients reported events ( $\mathrm{n}=$ 21 ), and the overall risk estimate was similar for linagliptin (12 events; 2039 patients) and the total comparator group (9 events, 1275 patients), with a HR of 1.04 (95\% CI, 0.43-2.47). This was also the case in a sensitivity analysis of the smaller treatment cohort, excluding data beyond 12 weeks from 1 trial (1218.64) in which 107 
Table 4 Baseline demographics and clinical characteristics, including CV risk factors, of the main study cohort in the linagliptin safety analysis (of adjudicated events)

\begin{tabular}{|c|c|c|c|c|}
\hline & $\begin{array}{l}\text { Linagliptin } \\
(n=5847)\end{array}$ & $\begin{array}{l}\text { *Active comparators } \\
(n=937)\end{array}$ & $\begin{array}{l}\text { Placebo } \\
(n=2675)\end{array}$ & $\begin{array}{l}\text { Total comparators } \\
(\mathrm{n}=3612)\end{array}$ \\
\hline Gender, $\%$ of patients Male/female & $54.4 / 45.6$ & $62.5 / 37.5$ & $54.3 / 45.7$ & $56.5 / 43.5$ \\
\hline Age, years & $59 \pm 11$ & $60 \pm 10$ & $58 \pm 11$ & $59 \pm 10$ \\
\hline $\mathrm{BMI}, \mathrm{kg} / \mathrm{m}^{2}$ & $29.0 \pm 5.2$ & $29.5 \pm 4.8$ & $29.5 \pm 5.3$ & $29.5 \pm 5.2$ \\
\hline \multicolumn{5}{|l|}{ Race, $\%$ of patients } \\
\hline White & 58.2 & 70.3 & 57.2 & 60.6 \\
\hline Black & 3.7 & 1.9 & 6.8 & 5.5 \\
\hline Asian & 38.1 & 27.7 & 36.0 & 33.8 \\
\hline $\mathrm{HbA} 1 \mathrm{c}, \mathrm{mmol} / \mathrm{mol}$ & $65 \pm 10$ & $61 \pm 9$ & $67 \pm 10$ & $65 \pm 10$ \\
\hline $\mathrm{HbA} 1 \mathrm{c}, \%$ & $8.1 \pm 0.9$ & $7.8 \pm 0.9$ & $8.3 \pm 0.9$ & $8.1 \pm 0.9$ \\
\hline $\mathrm{FPG}, \mathrm{mmol} / \mathrm{L}$ & $9.2 \pm 2.5$ & $9.2 \pm 2.2$ & $9.3 \pm 2.7$ & $9.3 \pm 2.6$ \\
\hline \multicolumn{5}{|l|}{ Diabetes duration, $\%$ of patients } \\
\hline$\leq 1$ year & 13.4 & 8.4 & 14.5 & 13.0 \\
\hline $1-5$ years & 31.7 & 38.8 & 27.3 & 30.3 \\
\hline$>5$ years & 54.9 & 52.7 & 58.2 & 56.8 \\
\hline \multicolumn{5}{|l|}{ Previous oral glucose-lowering agents, \% of patients } \\
\hline None & 16.4 & 9.6 & 19.4 & 16.8 \\
\hline 1 & 43.2 & 64.1 & 39.0 & 45.5 \\
\hline 2 & 39.3 & 26.1 & 40.0 & 36.0 \\
\hline$\geq 3$ & 1.1 & 0.1 & 2.1 & 1.6 \\
\hline \multicolumn{5}{|l|}{ Antidiabetic drugs at enrolment, $\%$ of patients } \\
\hline Metformin only & 31.8 & 60.1 & 20.7 & 31.0 \\
\hline Metformin + other antidiabetic agents & 38.1 & 25.2 & 38.2 & 34.9 \\
\hline Sulfonylurea only & 6.5 & 2.0 & 8.0 & 6.5 \\
\hline Sulfonylurea + other antidiabetic agents & 0.7 & 1.0 & 0.6 & 0.7 \\
\hline Insulin only & 3.8 & 0.0 & 9.3 & 6.9 \\
\hline Insulin + other antidiabetic agents & $<0.1$ & 0.0 & 0.0 & 0.0 \\
\hline \multicolumn{5}{|l|}{$\mathrm{CV}$ risk factors, $\%$ of patients } \\
\hline Metabolic syndrome $^{\dagger}$ & 46.5 & 67.7 & 46.6 & 52.1 \\
\hline Coronary artery disease & 11.8 & 12.3 & 14.1 & 13.6 \\
\hline Cerebrovascular disease & 3.6 & 4.2 & 4.9 & 4.7 \\
\hline Peripheral artery disease & 3.1 & 3.3 & 4.2 & 4.0 \\
\hline Hypertension & 63.9 & 73.0 & 65.7 & 67.6 \\
\hline Ex-/current smoker & 23.0/14.4 & $29.7 / 15.8$ & $22.4 / 13.4$ & 24.3/14.0 \\
\hline Microalbuminuria, \% (UACR >30 to $\leq 300 \mathrm{mg} / \mathrm{g}$ ) & 24.3 & 21.6 & 23.0 & 22.7 \\
\hline \multicolumn{5}{|c|}{ Renal function based on eGFR (MDRD formula),\% of patients } \\
\hline Normal $(\geq 90)$ & 43.5 & 43.3 & 41.1 & 41.7 \\
\hline Mildly impaired (60 to <90) & 45.5 & 49.8 & 43.5 & 45.1 \\
\hline Moderately impaired (30 to <60) & 8.9 & 6.8 & 10.8 & 9.7 \\
\hline Severely impaired $(<30)$ & 1.9 & 0.0 & 4.1 & 3.0 \\
\hline \multicolumn{5}{|l|}{ CV medication, $\%$ of patients } \\
\hline Acetyl-salicylic acid & 31.8 & 32.3 & 34.5 & 33.9 \\
\hline Antihypertensive & 60.9 & 69.6 & 62.0 & 64.0 \\
\hline Lipid-lowering therapy & 41.7 & 49.0 & 43.6 & 45.0 \\
\hline
\end{tabular}


Table 4 Baseline demographics and clinical characteristics, including CV risk factors, of the main study cohort in the linagliptin safety analysis (of adjudicated events) (Continued)

\begin{tabular}{llll}
\hline Any of the above & 72.7 & 81.6 & 73.9 \\
Framingham 10-year CV risk score & & & 75.9 \\
Score, $\%$ & $9.7 \pm 8.2$ & $11.7 \pm 8.6$ & $9.6 \pm 8.4$ \\
Score $>15 \%, \%$ of patients & 24.5 & 38.1 & 25.8 \\
\hline
\end{tabular}

$B M I$, body mass index; $C V$, cardiovascular; $e G F R$, estimated glomerular filtration rate; FPG, fasting plasma glucose; HbA1c, glycated hemoglobin; MDRD, Modification of Diet in Renal Disease; UACR, urinary albumin:creatinine ratio.

${ }^{*}$ Glimepiride $(n=775)$, voglibose $(n=162)$.

'International Diabetes Federation definition.

Values are mean $\pm S D$, unless otherwise stated.

placebo-treated patients were switched to treatment with glimepiride. In this sensitivity analysis, the total number of adjudicated CHF events was 9 in the linagliptin group and 5 in the placebo group, yielding a non-significant HR of 1.29 (95\% CI, 0.43-3.87).

In addition to the evaluation of hospitalization for heart failure in the 8 studies in which adjudication took place, further analysis of investigator-reported and nonadjudicated events from 24 placebo-controlled studies of linagliptin $5 \mathrm{mg}$ versus placebo showed that events suggestive of heart failure were reported in $0.5 \%(n=26)$ of linagliptin- and $0.2 \%(\mathrm{n}=8)$ of placebo-treated patients
(Table 10). Among these events, those considered to be serious were reported in $0.3 \%(n=16)$ of linagliptin- and $0.2 \%(n=6)$ of placebo-treated patients.

\section{Discussion}

This comprehensive pooled analysis evaluated patientlevel data from 9459 subjects with T2DM who participated in 19 clinical trials. It represents a collective 4421.3 patient-years of exposure to linagliptin-approximately twice as many years of exposure as previous analyses. In line with the conclusion of the previous analysis, this new analysis also suggests that linagliptin does not increase $\mathrm{CV}$

Table 5 Baseline demographics and clinical characteristics, including CV risk factors for the CHF analysis (of investigator-reported events)

\begin{tabular}{|c|c|c|}
\hline & Linagliptin $(n=5488)$ & Placebo $(n=3290)$ \\
\hline Gender, $\%$ of patients Male/female & $53.5 / 46.5$ & $54.9 / 45.1$ \\
\hline Age, years & $58.2 \pm 10.6$ & $58.1 \pm 10.6$ \\
\hline $\mathrm{BMI}, \mathrm{kg} / \mathrm{m}^{2}$ & $29.3 \pm 5.3$ & $30.0 \pm 5.4$ \\
\hline \multicolumn{3}{|l|}{ Race, $\%$ of patients } \\
\hline White & 59.5 & 63.0 \\
\hline Black & 4.3 & 7.4 \\
\hline Asian & 36.2 & 29.6 \\
\hline $\mathrm{HbA} 1 \mathrm{c}, \mathrm{mmol} / \mathrm{mol}$ & $66.1 \pm 9.8$ & $66.1 \pm 9.8$ \\
\hline $\mathrm{HbA} 1 \mathrm{c}, \%$ & $8.2 \pm 0.9$ & $8.2 \pm 0.9$ \\
\hline $\mathrm{FPG}, \mathrm{mg} / \mathrm{dL}$ & $166.2 \pm 45.7$ & $168.2 \pm 47.4$ \\
\hline \multicolumn{3}{|l|}{ Diabetes duration, $\%$ of patients } \\
\hline$\leq 1$ year & 15.4 & 15.8 \\
\hline $1-5$ years & 30.6 & 30.3 \\
\hline$>5$ years & 53.9 & 53.7 \\
\hline Missing & 0.1 & 0.2 \\
\hline \multicolumn{3}{|c|}{ Antidiabetes drugs at enrolment, $\%$ of patients } \\
\hline None & 21.7 & 25.6 \\
\hline 1 & 38.9 & 39.1 \\
\hline 2 & 38.1 & 33.5 \\
\hline$\geq 3$ & 1.2 & 1.7 \\
\hline
\end{tabular}

$B M I$, body mass index; $C H F$, congestive heart failure; $C V$, cardiovascular; $F P G$, fasting plasma glucose; HbA1c, glycated hemoglobin; MDRD, Modification of Diet in Renal Disease.

Values are mean $\pm S D$, unless otherwise stated. 
Table 6 Change in CV risk factors from baseline to last treatment (treated set)

\begin{tabular}{|c|c|c|c|c|}
\hline Mean (SEM) & Linagliptin $(n=5758)$ & Active comparators $(n=918)$ & Placebo $(n=2618)$ & Total comparators $(n=3536)$ \\
\hline \multicolumn{5}{|l|}{ Total cholesterol, mg/dL } \\
\hline Baseline & $187(0.6)$ & $186(1.3)$ & $187(0.9)$ & $187(0.8)$ \\
\hline Change from baseline & $1(0.5)$ & $2(1.1)$ & $2(0.7)$ & $2(0.6)$ \\
\hline \multicolumn{5}{|l|}{$\mathrm{LDL}, \mathrm{mg} / \mathrm{dL}$} \\
\hline Baseline & $107(0.5)$ & $104(1.1)$ & $107(0.7)$ & $106(0.6)$ \\
\hline Change from baseline & $1(0.4)$ & $4(0.9)$ & $1(0.6)$ & $1(0.5)$ \\
\hline \multicolumn{5}{|l|}{$\mathrm{HDL}, \mathrm{mg} / \mathrm{dL}$} \\
\hline Baseline & $47(0.2)$ & $48(0.4)$ & $47(0.3)$ & $47(0.2)$ \\
\hline Change from baseline & $1(0.1)$ & $-1(0.2)$ & $1(0.2)$ & $1(0.1)$ \\
\hline \multicolumn{5}{|l|}{ Triglyceride, mg/dL } \\
\hline Baseline & $173(1.8)$ & $180(4.1)$ & $174(2.9)$ & $176(2.4)$ \\
\hline Change from baseline & $-7(1.5)$ & $-8(4.2)$ & $-3(2.6)$ & $-5(2.2)$ \\
\hline \multicolumn{5}{|l|}{$\mathrm{HbA} 1 \mathrm{c}, \%$} \\
\hline Baseline & $8.1(0.01)$ & $7.8(0.03)$ & $8.3(0.02)$ & $8.1(0.02)$ \\
\hline Change from baseline & $-0.7(0.01)$ & $-0.5(0.03)$ & $-0.3(0.02)^{*}$ & $-0.3(0.02)$ \\
\hline \multicolumn{5}{|l|}{ Weight } \\
\hline Baseline & $79.5(0.25)$ & $83.8(0.58)$ & $81.1(0.39)$ & $81.9(0.32)$ \\
\hline Change from baseline & $-0.1(0.05)$ & $1.3(0.15)$ & $0.1(0.07)$ & $0.4(0.06)$ \\
\hline \multicolumn{5}{|l|}{ Systolic BP (mmHg) } \\
\hline Baseline & $131(0.2)$ & $134(0.5)$ & $132(0.3)$ & $132(0.3)$ \\
\hline Change from baseline & $-1(0.2)$ & $-1(0.5)$ & $-1(0.3)$ & $-1(0.3)$ \\
\hline \multicolumn{5}{|l|}{ Diastolic BP (mmHg) } \\
\hline Baseline & $78(0.1)$ & $80(0.3)$ & $78(0.2)$ & $79(0.2)$ \\
\hline Change from baseline & $-1(0.1)$ & $-1(0.3)$ & $-1(0.2)$ & $-1(0.2)$ \\
\hline \multicolumn{5}{|l|}{ Heart rate, bpm } \\
\hline Baseline & $74(0.1)$ & $73(0.4)$ & $74(0.2)$ & $74(0.2)$ \\
\hline Change from baseline & $1(0.1)$ & $-1(0.3)$ & $1(0.3)$ & $1(0.2)$ \\
\hline
\end{tabular}

$B P$, blood pressure; $b p m$, beats per minute; $C V$, cardiovascular; $H b A 1 c$, glycated hemoglobin; $H D L$, high-density lipoprotein; $L D L$, low-density lipoprotein.

${ }^{*}$ Analysis includes data obtained after initiation of glycemic rescue.

risk or $\mathrm{CV}$ outcomes versus combined comparator therapies or versus placebo, in patients with T2DM [18]. Furthermore, the findings of this analysis also indicate that the $\mathrm{CV}$ risk profile was not influenced by a number of important factors associated with $\mathrm{CV}$ complications (age, gender, race, use of rescue medication, occurrence of hypoglycemia, Framingham CHD risk, renal disease, and microalbuminuria). The findings of the present analysis add to the existing evidence base for DPP-4 inhibitors, which shows the class to be generally well tolerated, but with less definitive evidence regarding CV safety [19].

To enable a relevant assessment of CV risk, studies evaluating the CV safety of glucose-lowering therapies should include patients at increased risk of CV events, such as those with relatively advanced disease, elderly patients, and those with some degree of renal impairment [11]. In the present analysis, baseline data on the Framingham risk status of participants indicated that about $30 \%$ of patients had a 10 -year risk score of $>15 \%$, that approximately half of all patients had been diagnosed with T2DM for $>5$ years, and that around $13 \%$ of patients were older than 70 years of age. In addition, some degree of renal impairment (eGFR based on MDRD staging of $<90 \mathrm{~mL} / \mathrm{min}$ ) was present in just over half of patients analyzed (56.3\% in the linagliptin and $57.9 \%$ in total comparator groups, respectively), with nearly a quarter ( $24.3 \%$ and $22.7 \%$, respectively) having microalbuminuria. Thus, a sizeable proportion of the analyzed population may be deemed to exhibit moderately increased CV risk. Indeed, the observed incidence of rates of 4P-MACE (13.4 events and 18.9 events per 1000 patient-years for linagliptin- and active comparatortreated groups, respectively) is slightly higher than would be predicted from the Framingham risk scores. This observation, combined with the large number of patients exposed to linagliptin and the higher number of 
Table 7 Incidence and incidence rates of primary, secondary, and tertiary end points

\begin{tabular}{|c|c|c|c|c|}
\hline & \multicolumn{2}{|c|}{ Linagliptin $(n=5847)$} & \multicolumn{2}{|c|}{ Total comparators $(n=3612)$} \\
\hline & $\begin{array}{l}\text { Incidence } \\
\text { n (\%) }\end{array}$ & $\begin{array}{l}\text { Incidence rate } \\
\text { (per } 1000 \text { years) }\end{array}$ & $\begin{array}{l}\text { Incidence } \\
\mathrm{n}(\%)\end{array}$ & $\begin{array}{l}\text { Incidence rate } \\
\text { (per } 1000 \text { years) }\end{array}$ \\
\hline \multicolumn{5}{|l|}{ Primary end points } \\
\hline CV death, stroke, MI, or UAP with hospitalization & $60(1.0)$ & 13.4 & $62(1.7)$ & 18.9 \\
\hline \multicolumn{5}{|l|}{ Secondary end points } \\
\hline CV death, stroke, or Ml & $42(0.7)$ & 9.3 & $46(1.3)$ & 14.0 \\
\hline All major CV events & $96(1.6)$ & 21.5 & $95(2.6)$ & 29.1 \\
\hline FDA-custom MACE & $39(0.7)$ & 8.7 & $45(1.3)$ & 13.7 \\
\hline \multicolumn{5}{|l|}{ Tertiary end points } \\
\hline CV death & $11(0.2)$ & 2.4 & $8(0.2)$ & 2.4 \\
\hline Non-fatal Ml & $23(0.4)$ & 5.1 & $20(0.6)$ & 6.1 \\
\hline Non-fatal stroke & $9(0.2)$ & 2.0 & $19(0.5)$ & 5.8 \\
\hline TIA & $1(0.02)$ & 0.2 & $8(0.2)$ & 2.4 \\
\hline UAP with hospitalization & $22(0.4)$ & 4.9 & $16(0.4)$ & 4.8 \\
\hline Hospitalization for CHF* & $12(0.6)$ & 8.8 & $9(0.7)$ & 8.4 \\
\hline Total mortality & $18(0.3)$ & 4.0 & $16(0.4)$ & 4.8 \\
\hline
\end{tabular}

$C H F$, congestive heart failure; $C V$, cardiovascular; $F D A$, Food and Drug Administration; $M A C E$, major adverse $C V$ events; $M I$, myocardial infarction; $T I A$, transient ischemic attack; UAP, unstable angina pectoris.

*Includes data only from trials with prospective independent adjudication of hospitalization for CHF $(n=3314)$.

$\mathrm{CV}$ events accrued compared with previous analyses, therefore, supports the validity of the findings.

As noted above, the incidence of $\mathrm{CV}$ events reported in this analysis, per 1000 patient-years of exposure, was 13.4 for linagliptin and 18.9 for total comparators. Other, similar, analyses of phase 3 studies have reported incidence rates for custom MACE ranging from 5.8 to 14.6 for sitagliptin, saxagliptin, or vildagliptin, and 9.0 to 14.1 for pooled comparators [20-22]. The most recent assessment of the CV safety of sitagliptin, based on pooled data from 25 double-blind studies, showed an incidence rate ratio, per 100 patient-years, of 0.83 (95\% CI, 0.531.30) for the comparison of sitagliptin versus pooled comparators, and 1.01 (95\% CI, 0.55-1.86) for sitagliptin versus placebo [23]. These findings are in line with the results of the present analysis. Although the previous analyses of the CV safety of DPP-4 inhibitors differ in their methods, the findings nonetheless support the hypothesis that, in general, DPP-4 inhibitor therapy is not associated with increased CV risk. This was also supported by the neutral outcomes on 3P-MACE of the prospective studies SAVOR-TIMI 53 and EXAMINE,

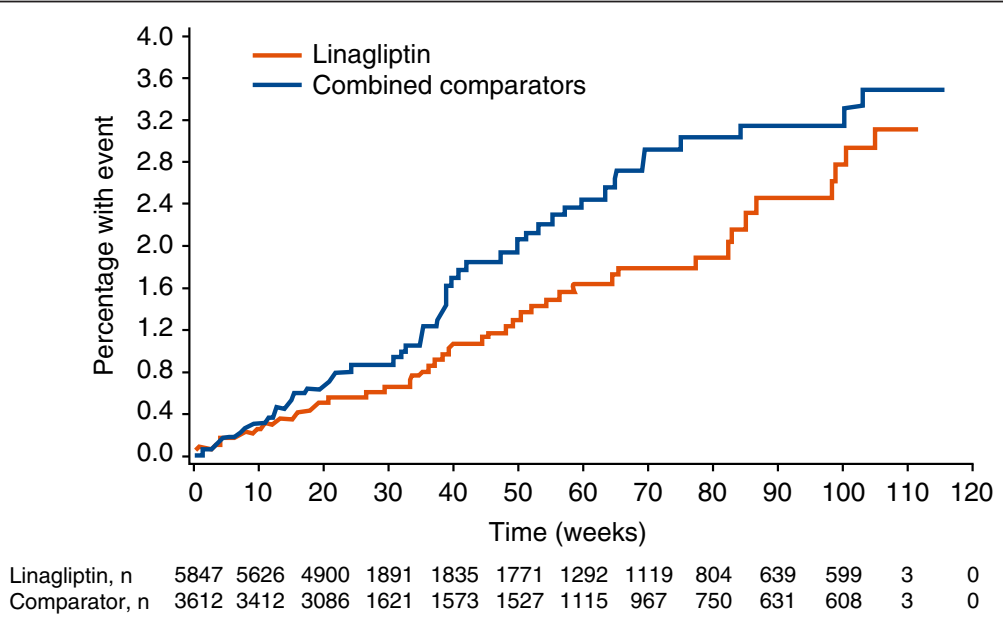

Figure 1 Time to first event (occurrence of any component of the 4P-MACE composite of CV death, Ml, stroke, or UAP with hospitalization) for patients receiving linagliptin versus total comparators. CV, cardiovascular; MI, myocardial infarction; UAP, unstable angina pectoris. 
Table 8 Risk for primary, secondary, and tertiary individual CV end points with linagliptin versus total comparators based on Cox proportional hazards model Cox HR $(95 \% \mathrm{Cl})$

\begin{tabular}{ll}
\hline Primary end point & \\
CV death, Ml, stroke, or & $0.78(0.55-1.12)$ \\
UAP with hospitalization & \\
Secondary end points & \\
CV death, stroke, or Ml & $0.74(0.49-1.13)$ \\
All major CV events & $0.82(0.61-1.09)$ \\
FDA-custom MACE & $0.70(0.45-1.08)$ \\
Tertiary end points & \\
CV death & $1.04(0.42-2.60)$ \\
Non-fatal MI & $0.86(0.47-1.56)$ \\
Non-fatal stroke & $0.34(0.15-0.75)$ \\
TIA & $0.09(0.01-0.75)$ \\
UAP with hospitalization & $1.08(0.56-2.06)$ \\
Hospitalization for CHF* & $1.04(0.43-2.47)$ \\
Total mortality & $0.89(0.45-1.75)$ \\
\hline
\end{tabular}

$C H F$, congestive heart failure; $C l$, confidence interval; $C V$, cardiovascular; $F D A$, Food and Drug Administration; $H R$, hazard ratio; $M A C E$, major adverse CV events; $M I$, myocardial infarction; TIA, transient ischemic attack; UAP, unstable angina pectoris.

*Includes data only from 8 trials with prospective independent adjudication of hospitalization for CHF $(n=3314)$.

conducted in patients with $\mathrm{T} 2 \mathrm{DM}$ at high $\mathrm{CV}$ risk $[12,13]$.

EXAMINE was designed to investigate the $\mathrm{CV}$ risk of alogliptin compared with placebo in patients with T2DM and recent acute coronary syndrome [13]. Similar rates of major CV AEs in addition to $\mathrm{CV}$ or all-cause mortality were reported for alogliptin- and placebo-treated patients. The SAVOR TIMI 53 trial evaluated the effects of saxagliptin on $\mathrm{CV}$ outcomes in patients with T2DM at high CV risk. No difference in the primary composite end point of $\mathrm{CV}$ death, MI, or ischemic stroke was found in saxagliptin- or placebo-treated patients [12]. It should be noted that both of these trials were relatively short in duration (median follow-up, respectively, 2.2 and 1.5 years) and included patients predominantly, or exclusively, with manifest CV complications, 2 important considerations when assessing the potential $\mathrm{CV}$ risk modulation of any compound [24,25].

The unexpected finding of an increased risk of $\mathrm{CHF}$ in these trials merits further careful evaluation $[12,14,15]$. A recent study of echocardiograms from 254 patients with T2DM and existing CHF (New York Heart Association [NYHA] class I to III), who received vildagliptin or placebo for 52 weeks, found that vildagliptin therapy did not change the cardiac ejection fraction (the primary end point of the study), and was not associated with worsening of CHF (confirmed by a blinded adjudication committee); worsening CHF occurred in 22 patients in the placebo group compared with 23 in the vildagliptin group [26]. However, patients taking vildagliptin, compared with those taking placebo, showed unexpected increases in left ventricular end-diastolic volume $(P=.007)$, end-systolic volume $(P=.06)$, and stroke volume $(P=.002)$. The possible mechanisms underlying these observations are not fully understood. Two recent meta-analyses of available data from randomized clinical trials of DPP-4 inhibitors have indicated that these drugs could be associated with an increased risk of acute heart failure $[27,28]$. However, both meta-analyses included data from the SAVOR-TIMI 53 trial, the results of which strongly influence the overall findings. Furthermore, a new analysis of data from EXAMINE, presented at the Scientific Sessions of the American College of

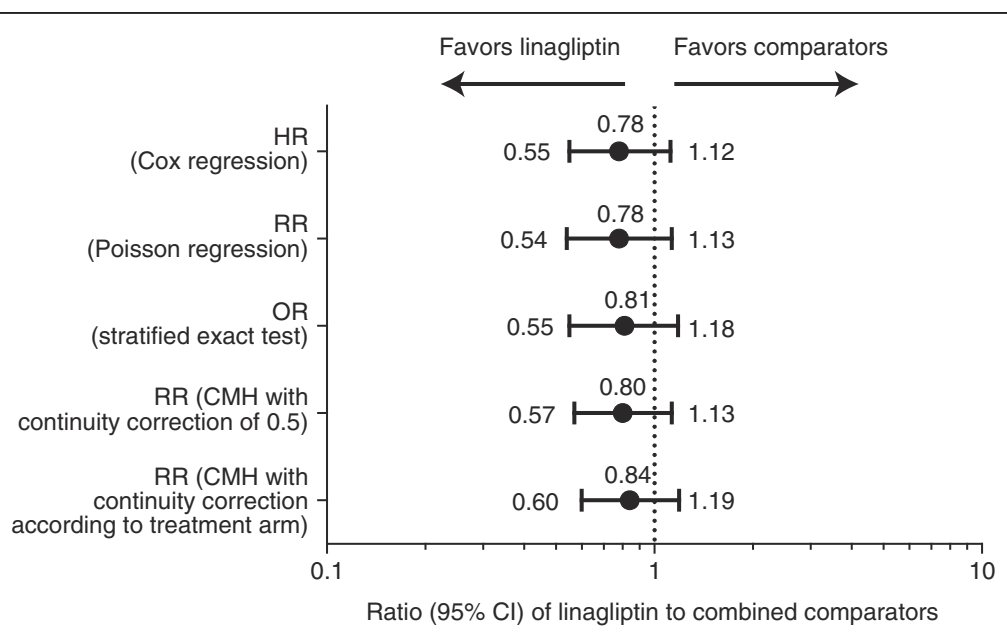

Figure 2 Risk estimates for primary composite CV end point with linagliptin versus total comparators based on various statistical models. Cl, confidence interval; $C M H$, Cochran-Mantel-Haenszel; $C V$, cardiovascular; HR, hazard ratio; OR, odds ratio; RR, risk ratio. 


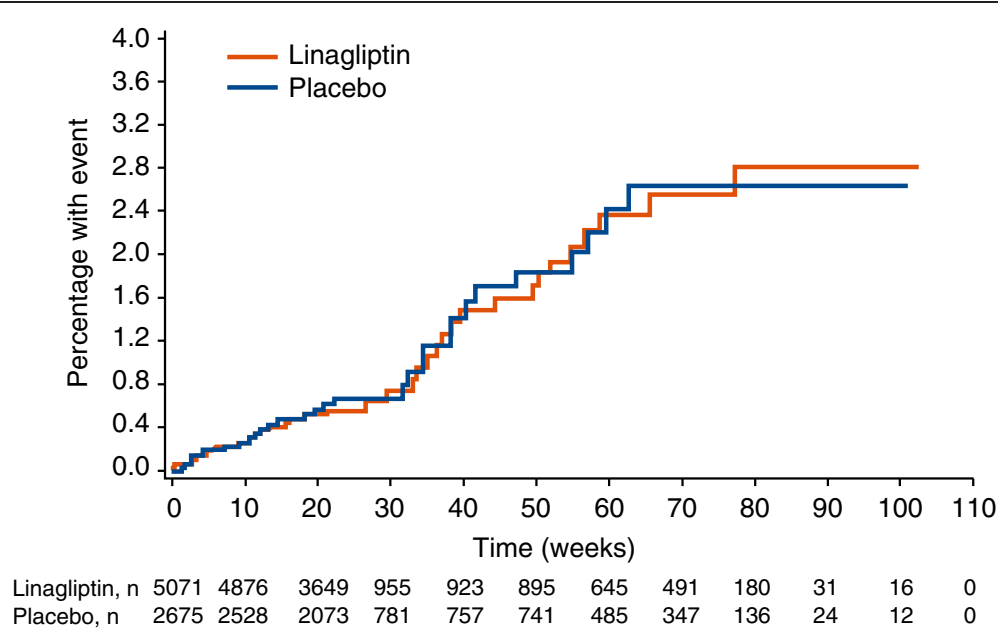

Figure 3 Time to first event (occurrence of any component of the 4 P-MACE composite) for patients receiving linagliptin versus placebo.

Cardiology in March 2014, indicated that alogliptin did not increase the risk of new-onset heart failure or the risk of readmission in patients with T2DM and a history of heart failure [29]. In the linagliptin clinical trial program, adjudication of hospitalization for CHF was implemented during phase $3 \mathrm{~b}$. Given the small number of reported cases of CHF (for the overall comparator analysis, $\mathrm{n}=12$ and $\mathrm{n}=9$; and for the comparison with placebo only, $n=9$ and $n=5$ ), the reported HR of 1.04 (95\% CI, 0.43-2.47) in the overall comparator analysis, or 1.29 (95\% CI, 0.43-3.87) in the placebo-only analysis must be interpreted with some caution. Similarly, in the additional analysis of investigator-reported AEs in 24 placebo-controlled studies, the occurrence of events suggestive of heart failure was low $(0.5 \%$ [ $n=26$ of 5488] and $0.2 \%$ [ $n=8$ of 3290] for linagliptin- and placebotreated patients, respectively), and was within the expected background incidence for this population. Therefore, this database is currently too small to allow firm conclusions to be made regarding the impact of linagliptin on the risk of heart failure. So far, there has been no explanation for the increase in risk of CHF observed in the trials mentioned above, and data are currently limited. However, it has been noted that trials with reported $\mathrm{CV}$ outcomes tend to include patients who are older, have a longer duration of T2DM, more CV risk factors, lower renal function, more comorbidities, and often treated with a greater number of antidiabetic drugs, including insulin, when compared with other studies of patients with T2DM [19]. These factors might be relevant in the identification of subpopulations who could be at increased risk of CHF or other CV outcomes with DPP-4 inhibitor therapy. Reassuringly, a review of safety data for DPP-4 inhibitors has demonstrated the safety and tolerability of these agents in fragile populations such as elderly patients and individuals with renal impairment [30]. Similarly, a recent pooled analysis of 6 clinical trials demonstrated the safety and tolerability of linagliptin in a vulnerable subpopulation of patients at high risk of renal or CV disease [31]. A recent systematic review and network meta-analysis of 10 clinical trials of DPP-4 inhibitors in patients requiring third-line therapy for T2DM showed no difference between these agents and placebo in the incidence of adverse events, including CVD [32]. This analysis thus provides further evidence of the safety and tolerability of DPP-4 inhibitors in patients with T2DM that is difficult to control.

The ongoing Trial Evaluating Cardiovascular Outcomes with Sitagliptin (TECOS), designed to test the hypothesis that sitagliptin added to usual diabetes care does not increase CV risk in patients with existing CVD (estimated mean trial duration, approximately 4 years) [33], will also provide an evaluation of DPP-4 inhibitor therapy over a longer period than SAVOR-TIMI 53 or EXAMINE, and should provide additional information on the CHF issue.

An interesting finding of the present pooled analysis is the significant reduction in cerebrovascular end points observed in linagliptin-treated patients, compared with the other groups, albeit limited by small number of observations. This finding would need to be further evaluated, in particular because similar results were not observed in the recent SAVOR-TIMI 53 and EXAMINE trials [12-14]. Whether linagliptin could offer benefits following stroke is another possible area for further research in light of preclinical findings that have demonstrated a glucose-independent neuroprotective effect of linagliptin in the diabetic mouse brain model, possibly as a result of neural stem cell proliferation [34]. Potential improvements in endothelial function with DPP-4 inhibition, as indicated in some studies, could have implications for cerebrovascular outcomes $[35,36]$. The impact 
Table 9 Subgroup analyses of primary end point for linagliptin versus total comparators based on proportional Cox hazards model and CMH test

\begin{tabular}{|c|c|c|c|c|}
\hline & $\begin{array}{l}\text { Linagliptin,patients with } \\
\text { events/total patients }\end{array}$ & $\begin{array}{l}\text { Total comparators, patients } \\
\text { with events/total patients }\end{array}$ & $\begin{array}{l}\text { Cox HR } \\
(95 \% \mathrm{Cl}) \\
\end{array}$ & $\begin{array}{l}\text { Incidence ratio } \\
(95 \% \mathrm{CI}) \mathrm{CMH} \text { Test }\end{array}$ \\
\hline \multicolumn{5}{|l|}{ Age (years) } \\
\hline$\leq 50$ & $5 / 1288$ & $3 / 781$ & $1.31(0.31-5.58)$ & $1.11(0.47-2.63)$ \\
\hline 51 to $<65$ & $26 / 2817$ & $26 / 1740$ & $0.75(0.43-1.30)$ & $0.86(0.52-1.41)$ \\
\hline 65 to 75 & $26 / 1418$ & 29/902 & $0.78(0.46-1.32)$ & $0.84(0.52-1.37)$ \\
\hline$\geq 75$ & $3 / 324$ & $4 / 189$ & $0.63(0.14-2.85)$ & $0.88(0.37-2.08)$ \\
\hline \multicolumn{5}{|l|}{ Gender } \\
\hline Male & $42 / 3183$ & $50 / 2039$ & $0.69(0.45-1.04)$ & $0.73(0.49-1.08)$ \\
\hline Female & $18 / 2664$ & $12 / 1573$ & $1.22(0.58-2.55)$ & $1.27(0.68-2.36)$ \\
\hline \multicolumn{5}{|l|}{ Race } \\
\hline White & $46 / 3405$ & $49 / 2190$ & $0.78(0.52-1.17)$ & $0.83(0.56-1.23)$ \\
\hline Black & $4 / 215$ & $1 / 200$ & $3.92(0.44-35.08)$ & $1.50(0.55-4.11)$ \\
\hline Asian & 10/2227 & $12 / 1222$ & $0.59(0.25-1.37)$ & $0.76(0.39-1.49)$ \\
\hline \multicolumn{5}{|l|}{ Use of rescue medication } \\
\hline No & $43 / 5080$ & $46 / 2824$ & $0.70(0.46-1.07)$ & $0.75(0.50-1.12)$ \\
\hline Yes & $17 / 767$ & $16 / 788$ & $1.10(0.56-2.19)$ & $1.11(0.64-1.91)$ \\
\hline \multicolumn{5}{|c|}{ Investigator-reported hypoglycemia } \\
\hline No & $48 / 5197$ & $37 / 2918$ & $0.86(0.56-1.32)$ & $0.97(0.65-1.45)$ \\
\hline Yes & $12 / 650$ & $25 / 694$ & $0.79(0.39-1.59)$ & $0.78(0.41-1.47)$ \\
\hline \multicolumn{5}{|c|}{ Framingham 10-year CV risk score } \\
\hline$\leq 15 \%$ & 20/3797 & $24 / 2438$ & $0.65(0.36-1.18)$ & $0.76(0.45-1.29)$ \\
\hline$>15 \%$ & $36 / 1433$ & $38 / 1046$ & $0.85(0.54-1.35)$ & $0.91(0.60-1.39)$ \\
\hline \multicolumn{5}{|l|}{ Baseline microalbuminuria } \\
\hline Normal ( $\leq 30$ mg/g) & $25 / 3610$ & $25 / 2389$ & $0.84(0.48-1.47)$ & $0.91(0.56-1.50)$ \\
\hline Elevated (>30 to $\leq 300 \mathrm{mg} / \mathrm{g}$ ) & $21 / 1248$ & $21 / 771$ & $0.75(0.41-1.38)$ & $0.83(0.49-1.41)$ \\
\hline High (>300 mg/g) & $6 / 280$ & $14 / 241$ & $0.43(0.16-1.11)$ & $0.63(0.31-1.26)$ \\
\hline
\end{tabular}

$\mathrm{Cl}$, confidence interval; $\mathrm{CV}$, cardiovascular; $H R$, hazard ratio; $\mathrm{CMH}$ test, Cochran-Mantel-Haenszel test with treatment arm continuity correction.

of linagliptin on cerebrovascular events and post-stroke function is currently under investigation in 2 outcome trials, as discussed below.

As with all pooled analyses, the present analysis has several limitations; in particular, the relatively short and different durations of the included studies limit the extent of interpretations that can be made. Furthermore, despite a large cumulative patient exposure to linagliptin, individual patient exposure was for a maximum of 2.2 years, so the time available for the development of $\mathrm{CV}$ events, or modulation of $\mathrm{CV}$ risk, was limited. As might be expected, only a relatively small proportion of patients received triple therapy or insulin therapy at baseline, suggesting that a relatively limited number of patients in the study population had advanced T2DM. However, the robustness of the findings of the present study is supported by its pre-specified design, which incorporated independent prospective, blinded adjudication of CV events, and by the consistency of the results, both across the individual trials and across the different pools of results. However, none of the individual studies included in our analysis was powered or designed to assess $\mathrm{CV}$ risk or events.

Two ongoing CV outcome trials of linagliptin will provide a more definitive answer on the CV safety profile of linagliptin. One of these trials, the CARdiovascular Outcome Study of LINAgliptin versus Glimepiride in Patients with Type 2 Diabetes (CAROLINA) [37,38] (NCT01243424) started in 2010 and has randomized 6041 patients with early T2DM and predominantly medium CV risk, to treatment with either linagliptin or glimepiride. CAROLINA is the first head-to-head CV outcome trial of a DPP-4 inhibitor versus active comparator that is sufficiently powered to demonstrate potential differences in $\mathrm{CV}$ events between treatment groups. CAROLINA will allow an assessment of the impact of long-term linagliptin therapy in a population at lower overall CV risk, with the possibility of 


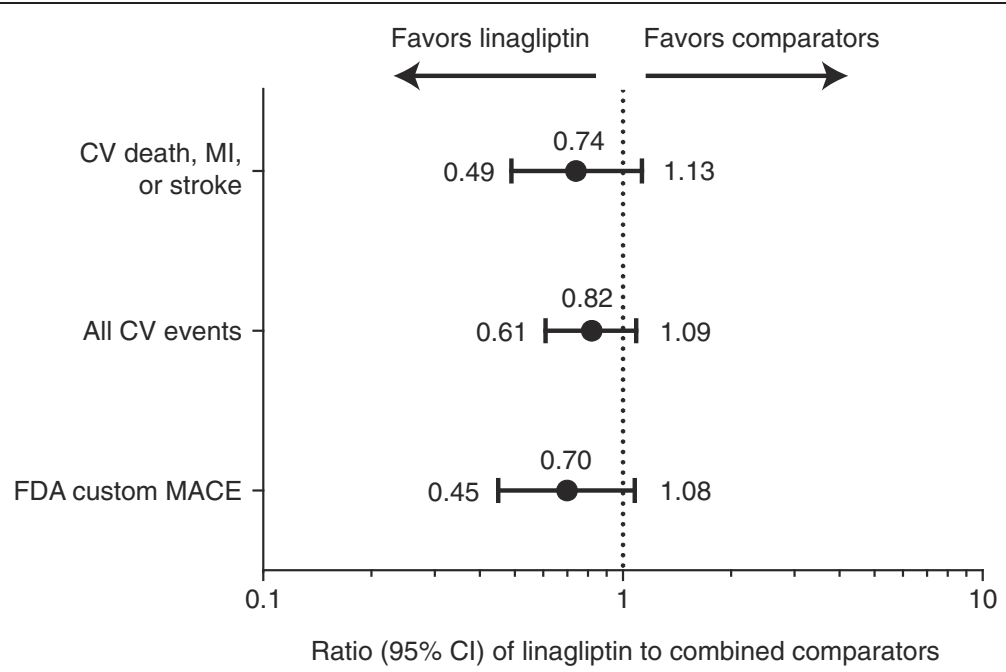

Figure $4 \mathrm{HR}$ estimates for secondary composite CV end points with linagliptin versus total comparators based on Cox hazard model. Cl, confidence interval; $C V$, cardiovascular; FDA, Food and Drug Administration; HR, hazard ratio; MACE, major adverse CV events; MI,

myocardial infarction.

demonstrating a CV benefit compared with the active comparator glimepiride.

The second CV outcome study, CARdiovascular Safety \& Clinical outcoME with LINAgliptin (CARMELINA'), will compare the CV and renal safety of linagliptin versus placebo, when added to standard care in approximately 8300 patients with T2DM at high CV and renal compromise, and is the only large outcome study dedicated to the evaluation of tangible renal outcomes with a DPP-4 inhibitor in comparison with placebo. The

Table 10 Occurrence of adverse events suggestive of heart failure in $\mathbf{2 4}$ placebo-controlled trials of linagliptin

\begin{tabular}{lll}
\hline & $\begin{array}{l}\text { Linagliptin } \\
(\mathbf{n}=\mathbf{5 4 8 8})\end{array}$ & $\begin{array}{l}\text { Placebo } \\
(\mathbf{n}=\mathbf{3 2 9 0})\end{array}$ \\
\hline Cardiac failure (narrow SMQ) ${ }^{*}, \mathrm{n}(\%)$ & $26(0.5)$ & $8(0.2)$ \\
Acute pulmonary edema & $1(0.0)$ & $1(0.0)$ \\
Cardiac failure & $6(0.1)$ & $2(0.1)$ \\
Cardiac failure, acute & $2(0.0)$ & $0(0.0)$ \\
Cardiac failure, chronic & $1(0.0)$ & $0(0.0)$ \\
Cardiac failure, congestive & $7(0.1)$ & $5(0.2)$ \\
Cardiogenic shock & $2(0.0)$ & $0(0.0)$ \\
Cardiopulmonary failure & $1(0.0)$ & $0(0.0)$ \\
Left ventricular failure & $6(0.1)$ & $0(0.0)$ \\
Pulmonary edema & $1(0.0)$ & $2(0.1)$ \\
Right ventricular failure & $1(0.0)$ & $0(0.0)$ \\
\hline
\end{tabular}

MedDRA, Medical Dictionary for Regulatory Activities; $S M Q$, standardized MedDRA queries.

Data are based on MedDRA version 16.0 .

* Heart failure data are a total of the narrow SMQ listed. Individual patients may have had $>1$ event.
CARMELINA $^{\circ}$ trial was initiated in 2013 and results are expected between 2017 and 2018.

\section{Conclusion}

This large patient-level pooled safety analysis of linagliptin supports previous findings that linagliptin is not associated with an increase in CV risk, compared with a pooled comparator group of placebo, glimepiride, or voglibose, in patients with T2DM, irrespective of background therapy. In this analysis, linagliptin has been shown to be effective in improving glycemic control in a broad range of patients with type 2 diabetes including elderly patients and those with renal impairment. The data presented here could help to reassure clinicians prescribing linagliptin to their patients that they do so without increasing $\mathrm{CV}$ risk. The ongoing CAROLINA and CARMELINA ${ }^{\circ}$ studies will provide definitive data on the CV safety of linagliptin.

\section{Abbreviations}

ACR: Albumin/creatinine ratio; AE: Adverse event; BI: Boehringer Ingelheim; BMI: Body mass index; BP: Blood pressure; bpm: Beats per minute;

CAROLINA: CARdiovascular Outcome Study of LINAgliptin versus Glimepiride in Patients with Type 2 Diabetes; CARMELINA: CARdiovascular Safety \&

Clinical outcoME with LINAgliptin; CEC: Clinical event committee;

CHD: Coronary heart disease; CHF: Congestive heart failure; $\mathrm{Cl}$ : Confidence interval; CMH: Cochran-Mantel-Haenszel; CV: Cardiovascular; CVD: Cardiovascular disease; DPP: Dipeptidyl peptidase; eGFR: Estimated glomerular filtration rate; FDA: US Food and Drug Administration; FPG: Fasting plasma glucose; HbA1c: Glycated hemoglobin; HDL: High-density lipoprotein; HR: Hazard ratio; LDL: Low-density lipoprotein; MACE: Major adverse CV event; MDRD: Modification of diet in renal disease; MedDRA: Medical dictionary for regulatory activities; MI: Myocardial infarction; NYHA: New York Heart Association; OR: Odds ratio; RR: Risk ratio; SAVOR TIMI 53: The Saxagliptin Assessment of Vascular Outcomes Recorded in Patients with Diabetes Mellitus - Thrombolysis in Myocardial Infarction 53 trial; SMQ: Standardized MedDRA queries; SU: Sulfonylurea; T2DM: Type 2 diabetes mellitus; TECOS: Trial evaluating cardiovascular outcomes with 
sitagliptin; TIA: Transient ischemic attack; UACR: Urinary albumin:creatinine ratio; UAP: Unstable angina pectoris.

\section{Competing interests}

JR has served on scientific advisory boards and received honorarium or consulting fees from Sanofi, Novo Nordisk, Eli Lilly, GlaxoSmithKline, Takeda, Merck, Daiichi Sankyo, Janssen, Novartis, Boehringer Ingelheim, MannKind, Intarcia, and Lexicon. In addition he has received grants/research support from Merck, Pfizer, Sanofi, Novo Nordisk, Roche, Bristol-Myers Squibb, Eli Lilly, GlaxoSmithKline, Takeda, Novartis, AstraZeneca, Amylin, Janssen, Daiichi Sankyo, MannKind, Boehringer Ingelheim, Intarcia, and Lexicon. NM has served as a consultant to AstraZeneca, Amgen, Bristol-Meyer Squibb, Boehringer Ingelheim, Merck, NovoNordisk, Roche, and Sanofi-Aventis. He has received grant support from Merck and Boehringer Ingelheim. In addition, he has served as a speaker for AstraZeneca, Amgen, Bayer, Bristol-Meyer Squibb, Boehringer Ingelheim, Lilly, Merck, Mitsubishi Tanabe Pharma Corporation, Novartis, NovoNordisk, Pfizer, Roche, and Sanofi-Aventis. DN, TS, SP, HJW, and OEJ are employees of Boehringer Ingelheim, the developer of linagliptin.

\section{Authors' contributions}

All authors assisted in drafting the manuscript, and read and approved the final version. In addition, OEJ conceived of the study and participated in its design and coordination, and interpretation of the data. JR participated in the study design, coordination, and data interpretation. DN participated in the design of the study and carried out the statistical analysis. NM, TS, SP, and HJW participated in the study design and interpretation of data.

\section{Acknowledgments}

This study was sponsored by Boehringer Ingelheim, the manufacturer of linagliptin, and by Eli Lily. The authors wrote and were fully responsible for all content and editorial decisions, were involved in all stages of manuscript development, and have approved the final version. OEJ, DN, TS, SP, and HJW are employees of the study sponsor and, in their authorship roles, were involved in the collection, analysis, and interpretation of data; in the writing of the manuscript; and in the decision to submit the manuscript for publication. Medical writing assistance, supported financially by Boehringer Ingelheim, was provided by Jennifer Edwards, MB BS, of Envision Scientific Solutions during the preparation of this manuscript.

\section{Prior Publication}

Some of the results included in this paper have been presented as abstracts at the 2013 Congresses of the American Heart Association, the European Association for the Study of Diabetes, and the American Diabetes Association.

\section{Author details}

${ }^{1}$ Dallas Diabetes and Endocrine Center at Medical City, Dallas, TX, USA. Department of Internal Medicine I, University Hospital Aachen, Aachen, Germany. ${ }^{3}$ Boehringer Ingelheim, Biberach, Germany. ${ }^{4}$ Boehringer Ingelheim, Ingelheim, Germany. ${ }^{5}$ Boehringer Ingelheim, Bracknell, Berkshire, UK. ${ }^{6}$ Boehringer Ingelheim, Drengsrudbekken 8, 1373 Asker, Oslo, Norway.

\section{Received: 17 March 2015 Accepted: 27 April 2015}

\section{Published online: 21 May 2015}

\section{References}

1. Huxley R, Barzi F, Woodward M. Excess risk of fatal coronary heart disease associated with diabetes in men and women: meta-analysis of 37 prospective cohort studies. BMJ. 2006;332(7533):73-8.

2. Morrish NJ, Wang SL, Stevens LK, Fuller JH, Keen H. Mortality and causes of death in the WHO Multinational Study of Vascular Disease in Diabetes. Diabetologia. 2001;44((Suppl 2)):S14-21.

3. Turner RC, Millns H, Neil HA, Stratton IM, Manley SE, Matthews DR, et al. Risk factors for coronary artery disease in non-insulin dependent diabetes mellitus: United Kingdom Prospective Diabetes Study (UKPDS: 23). BMJ. 1998;316(7134):823-8.

4. Nissen SE, Wolski K. Effect of rosiglitazone on the risk of myocardial infarction and death from cardiovascular causes. N Engl J Med. 2007;356(24):2457-71.

5. Rao AD, Kuhadiya N, Reynolds K, Fonseca VA. Is the combination of sulfonylureas and metformin associated with an increased risk of cardiovascular disease or all-cause mortality?: a meta-analysis of observational studies. Diabetes Care. 2008;31(8):1672-8.

6. Meinert CL, Knatterud GL, Prout TE, Klimt CR. A study of the effects of hypoglycemic agents on vascular complications in patients with adult-onset diabetes. II. Mortality results. Diabetes. 1970;19(Suppl):789-830.

7. Johnson JA, Majumdar SR, Simpson SH, Toth EL. Decreased mortality associated with the use of metformin compared with sulfonylurea monotherapy in type 2 diabetes. Diabetes Care. 2002;25(12):2244-8.

8. Evans JM, Ogston SA, Emslie-Smith A, Morris AD. Risk of mortality and adverse cardiovascular outcomes in type 2 diabetes: a comparison of patients treated with sulfonylureas and metformin. Diabetologia. 2006;49(5):930-6.

9. Klamann A, Sarfert P, Launhardt V, Schulte G, Schmiegel WH, Nauck MA. Myocardial infarction in diabetic vs non-diabetic subjects. Survival and infarct size following therapy with sulfonylureas (glibenclamide). Eur Heart J. 2000;21(3):220-9.

10. Zeller M, Danchin N, Simon D, Vahanian A, Lorgis L, Cottin Y, et al. Impact of type of preadmission sulfonylureas on mortality and cardiovascular outcomes in diabetic patients with acute myocardial infarction. J Clin Endocrinol Metab. 2010;95(11):4993-5002.

11. U.S. Department of Health and Human Services, Food and Drug Administration, Center for Drug Evaluation and Research (CDER). Guidance for Industry Diabetes Mellitus - Evaluating Cardiovascular Risk in New Antidiabetic Therapies to Treat Type 2 Diabetes. 2008. http://www.fda.gov/downloads/Drugs/ GuidanceComplianceRegulatoryInformation/Guidances/ucm071627.pdf. Accessed July 9, 2014.

12. Scirica BM, Bhatt DL, Braunwald E, Steg PG, Davidson J, Hirshberg B, et al. Saxagliptin and cardiovascular outcomes in patients with type 2 diabetes mellitus. N Engl J Med. 2013;369(14):1317-26.

13. White WB, Cannon CP, Heller SR, Nissen SE, Bergenstal RM, Bakris GL, et al. Alogliptin after acute coronary syndrome in patients with type 2 diabetes. $N$ Engl J Med. 2013;369(14):1327-35.

14. White W. Results from EXAMINE. Oral presentation at EASD 2013. http:// www.cardiotimes.com/documents/powerpoints/SLI064.ppt. Accessed May 26, 2015

15. Scirica BM, Braunwald E, Raz I, Cavender MA, Morrow DA, Jarolim P, et al. Heart Failure, Saxagliptin and Diabetes Mellitus: Observations from the SAVOR - TIMI 53 Randomized Trial. Circulation. 2014;130(18):1579-88.

16. Deacon CF, Holst JJ. Linagliptin, a xanthine-based dipeptidyl peptidase-4 inhibitor with an unusual profile for the treatment of type 2 diabetes. Expert Opin Investig Drugs. 2010;19(1):133-40.

17. Scheen AJ. Linagliptin for the treatment of type 2 diabetes (pharmacokinetic evaluation). Expert Opin Drug Metab Toxicol. 2011;7(12):1561-76.

18. Johansen OE, Neubacher D, von Eynatten M, Patel S, Woerle HJ. Cardiovascular safety with linagliptin in patients with type 2 diabetes mellitus: a pre-specified, prospective, and adjudicated meta-analysis of a phase 3 programme. Cardiovasc Diabetol. 2012;11:3.

19. Ceriello A, Sportiello L, Rafaniello C, Rossi F. DPP-4 inhibitors: pharmacological differences and their clinical implications. Expert Opin Drug Saf. 2014;13((Suppl 1)):S57-68.

20. Frederich R, Alexander JH, Fiedorek FT, Donovan M, Berglind N, Harris S, et al. A systematic assessment of cardiovascular outcomes in the saxagliptin drug development program for type 2 diabetes. Postgrad Med. 2010;122(3):16-27.

21. Williams-Herman D, Engel SS, Round E, Johnson J, Golm GT, Guo H, et al. Safety and tolerability of sitagliptin in clinical studies: a pooled analysis of data from 10,246 patients with type 2 diabetes. BMC Endocr Disord. 2010;10:7.

22. Schweizer A, Dejager S, Foley JE, Couturier A, Ligueros-Saylan M, Kothny W Assessing the cardio-cerebrovascular safety of vildagliptin: meta-analysis of adjudicated events from a large Phase III type 2 diabetes population. Diabetes Obes Metab. 2010;12(6):485-94.

23. Engel SS, Golm GT, Shapiro D, Davies MJ, Kaufman KD, Goldstein BJ. Cardiovascular safety of sitagliptin in patients with type 2 diabetes mellitus: a pooled analysis. Cardiovasc Diabetol. 2013;12:3.

24. Dzau V, Braunwald E. Resolved and unresolved issues in the prevention and treatment of coronary artery disease: a workshop consensus statement. Am Heart J. 1991;121(4 Pt 1):1244-63.

25. Lee SJ, Leipzig RM, Walter LC. Incorporating lag time to benefit into prevention decisions for older adults. JAMA. 2013;310(24):2609-10.

26. McMurray J. Vildagliptin shows no adverse effect on ejection fraction in diabetic patients with HF. Presented at the Heart Failure Congress 2013, Lisbon, Portugal, May 25-28, 2013. abstract. 
27. Monami M, Dicembrini I, Mannucci E. Dipeptidyl peptidase-4 inhibitors and heart failure: A meta-analysis of randomized clinical trials. Nutr Metab Cardiovasc Dis. 2014;24(7):689-97.

28. Wu S, Hopper I, Skiba M, Krum H. Dipeptidyl peptidase-4 inhibitors and cardiovascular outcomes: Meta-analysis of randomized clinical trials with 55,141 participants. Cardiovasc Ther. 2014;32(4):147-58.

29. Zannad F, Cannon C, Cushman W, Bakris G, Nissen S, Heller S, et al. Alogliptin in patients with type 2 diabetes after acute coronary syndromes: heart failure outcomes and cardiovascular safety in heart failure patients. J Am Coll Cardiol. 2014:63(12 S):A117.

30. Scheen AJ. Safety of dipeptidyl peptidase-4 inhibitors for treating type 2 diabetes. Expert Opin Drug Saf. 2015;14(4):505-24.

31. von Eynatten M, Gong Y, Emser A, Woerle HJ. Efficacy and safety of linagliptin in type 2 diabetes subjects at high risk for renal and cardiovascular disease: a pooled analysis of six phase III clinical trials. Cardiovasc Diabetol. 2013;12:60.

32. Tricco AC, Antony J, Khan PA, Ghassemi M, Hamid JS, Ashoor H, et al. Safety and effectiveness of dipeptidyl peptidase-4 inhibitors versus intermediate-acting insulin or placebo for patients with type 2 diabetes failing two oral antihyperglycaemic agents: a systematic review and network meta-analysis. BMJ Open. 2014;4(12), e005752.

33. Green JB, Bethel MA, Paul SK, Ring A, Kaufman KD, Shapiro DR, et al. Rationale, design, and organization of a randomized, controlled Trial Evaluating Cardiovascular Outcomes with Sitagliptin (TECOS) in patients with type 2 diabetes and established cardiovascular disease. Am Heart J. 2013;166(6):983-9.

34. Darsalia V, Ortsater H, Olverling A, Darlof E, Wolbert P, Nystrom T, et al. The DPP-4 inhibitor linagliptin counteracts stroke in the normal and diabetic mouse brain: a comparison with glimepiride. Diabetes. 2013;62(4):1289-96.

35. Nakamura K, Oe H, Kihara H, Shimada K, Fukuda S, Watanabe K, et al. DPP-4 inhibitor and alpha-glucosidase inhibitor equally improve endothelial function in patients with type 2 diabetes: EDGE study. Cardiovasc Diabetol. 2014;13:110

36. Ott C, Raff U, Schmidt S, Kistner I, Friedrich S, Bramlage P, et al. Effects of saxagliptin on early microvascular changes in patients with type 2 diabetes. Cardiovasc Diabetol. 2014;13:19.

37. Rosenstock J, Marx N, Kahn SE, Zinman B, Kastelein JJ, Lachin JM, et al. Cardiovascular outcome trials in type 2 diabetes and the sulphonylurea controversy: Rationale for the active-comparator CAROLINA trial. Diab VasC Dis Res. 2013;10(4):289-301.

38. Marx N, Rosenstock J, Kahn SE, Zinman B, Kastelein JJ, Lachin JM, et al. Design and baseline characteristics of the CARdiovascular Outcome Trial of LINAgliptin Versus Glimepiride in Type 2 Diabetes: CAROLINA ${ }^{\circledR}$. Diab VasC Dis Res. 2015;12(3):164-74.

39. Gomis R, Espadero R-M, Jones R, Woerle HJ, Dugi KA. Efficacy and safety of initial combination therapy with linagliptin and pioglitazone in patients with inadequately controlled type 2 diabetes: a randomized, double-blind, placebo controlled study. Diabetes Obes Metab. 2011;13(7):653-61.

40. Del Prato S, Barnett AH, Huisman H, Neubacher D, Woerle HJ, Dugi KA Effect of linagliptin monotherapy on glycaemic control and markers of beta-cell function in patients with inadequately controlled type 2 diabetes: a randomized controlled trial. Diabetes Obes Metab. 2011;13(3):258-67.

41. Taskinen MR, Rosenstock J, Tamminen I, Kubiak R, Patel S, Dugi KA, et al. Safety and efficacy of linagliptin as add-on therapy to metformin in patients with type 2 diabetes: a randomized, double-blind, placebo-controlled study. Diabetes Obes Metab. 2011;13(1):65-74

42. Owens DR, Swallow R, Dugi KA, Woerle HJ. Efficacy and safety of linagliptin in persons with type 2 diabetes inadequately controlled by a combination of metformin and sulphonylurea: a 24 week randomised study. Diabet Med. 2011;28(11):1352-61

43. Heise T, Graefe-Mody EU, Huttner S, Ring A, Trommeshauser D, Dugi KA. Pharmacokinetics, pharmacodynamics and tolerability of multiple oral doses of linagliptin, a dipeptidyl peptidase-4 inhibitor in male type 2 diabetes patients. Diabetes Obes Metab. 2009;11(8):786-94.

44. Forst T, Uhlig-Laske B, Ring A, Ritzhaupt A, Graefe-Mody U, Dugi KA. The oral DPP-4 inhibitor linagliptin significantly lowers $\mathrm{HbA1c}$ after 4 weeks of treatment in patients with type 2 diabetes mellitus. Diabetes Obes Metab. 2011;13(6):542-50

45. Singh-Franco D, McLaughlin-Middlekauff J, Elrod S, Harrington C. The effect of linagliptin on glycaemic control and tolerability in patients with type 2 diabetes mellitus: a systematic review and meta-analysis. Diabetes Obes Metab. 2012:14(8):694-708.

46. Forst T, Uhlig-Laske B, Ring A, Graefe-Mody U, Friedrich C, Herbach K, et al Linagliptin (BI 1356), a potent and selective DPP-4 inhibitor, is safe and efficacious in combination with metformin in patients with inadequately controlled Type 2 diabetes. Diabet Med. 2010;27(12):1409-19.

47. Rauch T, Graefe-Mody U, Deacon CF, Ring A, Holst JJ, Woerle HJ, et al. Linagliptin increases incretin levels, lowers glucagon, and improves glycemic control in type 2 diabetes mellitus. Diabetes Ther. 2012;3(1):10.

\section{Submit your next manuscript to BioMed Central and take full advantage of:}

- Convenient online submission

- Thorough peer review

- No space constraints or color figure charges

- Immediate publication on acceptance

- Inclusion in PubMed, CAS, Scopus and Google Scholar

- Research which is freely available for redistribution 